\title{
Food Insecurity Among HIV Sero-Positive Patients
}

\author{
Tshililo AR MCur ${ }^{*}$ and Mangena-Netshikweta
}

Professor, University of Venda, South Africa

*Corresponding author: Mrs Tshililo AR MCur, Department of Advanced Nursing Science, University of Venda, P/Bag X5050, Thohoyandou, 0950, South Africa, Tel: 0159628840; E-mail: Rose.Tshililo@univen.ac.za

Received date: May 23, 2014, Accepted date: July 05, 2014, Published date: July 08, 2014

Copyright: (C) 2014 Cur TARM, et al. This is an open-access article distributed under the terms of the Creative Commons Attribution License, which permits unrestricted use, distribution, and reproduction in any medium, provided the original author and source are credited.

\begin{abstract}
Due to the uncertainties of job availabilities among rural communities, poverty stricken families find it hard to supply enough food to their family members. However, food insecurity has been defined by Weiser and Bangsberg as the limited or uncertain availability of nutritionally adequate, safe foods or the inability to acquire personally acceptable foods in socially acceptable ways. South African study by Mashau supported Mills and Bangsberg study by warning that hunger is the most extreme consequence of food insecurity. Tshililo also warned that immune system of a person with HIV and AIDS needs to be boosted with nutritious food. The broader concept encompassed problems with household food supply, quality of diet, feelings about the situation, and what effort was made to maintain household food supplies. The purpose of this study was to explore food insecurity among HI sero-positive patients in rural Vhembe district of Limpopo Province. A qualitative, exploratory, descriptive and contextual design was used. A non-probability, purposive sampling method was used to select family members who care for $\mathrm{HI}$ seropositive patients at home. In-depth interviews were conducted to 20 participants. Data were analyzed according to Tesch's open-coding method. This study revealed that due to financial constrains; family socio-economic status is affected. Therefore patient's conditions are deteriorated as well balanced diet cannot be maintained.
\end{abstract}

Keywords: HI seropositive patients; Food insecurity; Viral load suppression; Adherence; ARV's

\section{Introduction}

Human immunodeficiency virus (HIV) remains a global health problem. More than 30 million people around the world have died of acquired immune deficiency syndrome (AIDS) related diseases. At the end of 20106.7 million people were on antiretroviral treatment (ART) globally; 7.5 million people were still in need (ART) base on world Health organisation Guideline [1]. In 2011, South Africa was estimated to have 5.38 million people living with HIV and AIDS and 1.1 million of them were receiving Anti-Retroviral Therapy.

Food insecurity is known as the major influence in people with HIV, and comprises lack of access to food of sufficient quality and quantity to perform usual daily activities, as well as having limited or uncertain access to food that is nutritionally adequate, culturally acceptable, and safe. WHO indicated that hunger and food insecurity may disturb individual's nutritional state and also affects adherence to antiretroviral drugs thus hindering management of the disease [2].

According to UNAIDS lack of sufficient food in the diet has negative effects on HIV by impacting ability to take antiretroviral medications in a number of ways, including causing symptoms of nausea while taking medications on an empty stomach [3]. Adequate dietary intake and absorption are therefore essential for achieving the full benefits of ARV. They further argued that early nutritional support, advice and active support are recommended to delay the progression of HIV to AIDS. Moreover it is also revealed that people living with HIV (PLWHIV) 10-30\% higher energy requirements than a healthy person without HIV.

WHO (2006) supported that energy requirements of HIV-infected individuals increase by about $10 \%$ from the time of infection and by
$20 \%-30 \%$ when chronic opportunistic infections or HIV-specific conditions are present [4]. It was also supported by Tshililo that everyone including HIV positive patient has the right to a standard of living adequate for the health and well- being of himself and his family, including food [5]. Food availability and good nutrition are thus essential for keeping people living with HIV healthy for longer. A stronger, healthier body can better resist the opportunistic infections that affect people living with HIV, especially in resource-poor setting [3].

Consumption of a balanced healthy diet is vital for health and survival for all individuals regardless of HIV status. Good nutrition, on the other hand, gives strength, helps to maintain and improve performance of the immune system thereby protecting the body against infection and delaying progression of the disease. Though nutrition cannot cure AIDS or prevent HIV infection; however, people living with HIV who are well-nourished are stronger and better able to fight infections. Good nutrition will also complement and ensure effective antiretroviral treatment [2].

Nutritional care and support, which includes counselling, education, information-sharing and provision of food, is therefore a fundamental component of a comprehensive package of care and support for all PLWHIV. Ensuring that PLHIV have access to food of adequate quantity and quality at the individual and household levels is a critical part of their health care. Varied and healthy diets improve the body's utilisation of nutrients and contribute to the health of people living with HIV [2].

Adequate nutrition is essential to maintain a healthy immune system, sustain physical activity, and assure optimal quality of life. UNAIDS policy brief about HIV, food security and nutrition also supported that addressing food security and nutrition in all settings is vital to achieving the goal of universal access to HIV prevention, treatment, care and support by 2010 [3]. The purpose of this study was 
to explore food insecurity among HI Sero-positive patients in rural Vhembe district of Limpopo Province in South Africa.

In this study food insecurity refers to a situation where HIV positive patients are unable to get sufficient quantity of food available on a consistence basis, not having sufficient resources to obtain appropriate food and insufficient knowledge of basic nutrition and care.

\section{Methodology \\ Research design}

A qualitative, explorative, descriptive and contextual design was used to attain the objectives of the study. Qualitative research involves the systemic collection and analysis of subjective data which were provided by family members who care for HI seropositive patients at home regarding food insecurity [5].

\section{Population and sampling}

Purposive sampling was used to select family members caring for HI seropositive patients who are receiving ARV and who were willing to participate in the study. Research was conducted at their homes.

\section{Permission to conduct a study}

The proposal was presented to the University of Venda Higher Degrees Committee as well as the University of Venda Health, Safety and Research Ethics Committee and approval was granted. Permission was sought from the Provincial Department of Health and Welfare; District Department of Health.

\section{Informed consent}

Participants were given full information about the purpose of the study using the language that they understand. Ethical principles of voluntary participation, informed consent, confidentiality were considered throughout the study.

\section{Data collection}

Phenomenological interviews, observation and field notes were used to explore and describe food insecurity among HI Seropositive patients.

\section{Data analysis}

Qualitative data were analysed using Tesch steps of open coding [6]. Themes and sub-themes were emerged and they reflect the challenges that family members experience regarding food insecurity among HI seropositive patients.

\section{Measures to ensure trustworthiness}

Credibility was ensured by prolonged engagement, persistent observation and triangulation, full description of research methodology were provided to external experts to ensure dependability, for conformability raw data were written and tape recorded during semi-structured interview with participants and the researcher provided sufficient descriptive data in the report for consumers to evaluate the applicability of the data to other context to ensure transferability [7].

\section{Results}

\begin{tabular}{|l|l|l|l|}
\hline No & Themes No & Sub-themes \\
\hline 1 & $\begin{array}{l}\text { Decreased food consumption } \\
\text { related to debilitating nature of } \\
\text { patient's condition }\end{array}$ & 1.1 & $\begin{array}{l}\text { Inability to eat and swallow } \\
\text { because of painful sores in the } \\
\text { mouth and throat }\end{array}$ \\
\hline 2 & $\begin{array}{l}\text { Shortage of food due to altered } \\
\text { socio-economic status }\end{array}$ & 2.1 & $\begin{array}{l}\text { Loss of appetite due to } \\
\text { fatigue, depression and other } \\
\text { changes in the mental state }\end{array}$ \\
\hline $\begin{array}{l}\text { unable to secure job because } \\
\text { of the disease process }\end{array}$ \\
\hline 3 & $\begin{array}{l}\text { Insufficient knowledge regarding } \\
\text { the relationship between HIV and } \\
\text { nutrition }\end{array}$ & $\begin{array}{l}\text { Side effects of medication } \\
\text { nausea, vomiting } \\
\text { diarrhoea and }\end{array}$ \\
\hline
\end{tabular}

Table 1: Themes and sub-themes which were emerged during data analysis

\section{Discussion}

\section{Theme 1: Decreased food consumption related to debilitating nature of patient's condition.}

Adequate nutrition, which is best achieved through consumption of a balanced

Healthy diet is vital for health and survival for all individuals regardless of HIV status. Despite the fact that participants are making efforts of trying to secure adequate nutrition, they experience problems because their patients are unable to eat due to lack of appetite, vomiting, oral thrush and depression which often accompany HIV infection.

\section{Sub-theme 1.1 Inability to eat because of painful sores in the mouth and throat}

Participants indicated that they have a challenge when they want to feed their patients at home. The problem is in connection with sores in the mouth and throat that are manifested in HIV positive patients. With these sores patients are unable to take foods which are important to their life. Furthermore, even if they can take the food, they often vomit immediately after eating. Participant responded in this way:

"I have a problem that even though he wants to eat he cannot because of sores in the mouth and throat. I believe that if my son eats he would be getting better because I don't think medication that he is getting could work without food"

Studies also revealed that food insecurity can also affect adherence to antiretroviral drugs as well as their effectiveness. It was also discovered that lack of sufficient food can hinder management of HIV/ AIDS [2]. 
Sub-theme1.2: Loss of appetite due to fatigue, depression and other changes in the mental state

Despite the fact that participants know about the important of taking well balanced diet they face the challenge that their patients could not eat as they often suffer from lack of appetite due to fatigue and depression. This is supported by this quotation from participant:

"My husband is always depressed, even when I give him food to eat, he is reluctant. He even tells me that he can't see the reason for living and that is painful to me:

HIV-related infections, such as diarrhoea, have severe nutritional consequences that commonly precipitate appetite loss, weight loss and wasting [8].

\section{Sub-theme 1.3: Side effects of medication nausea, vomiting and diarrhoea}

Participants reported that since their patients started ART's they always suffer vomiting and diarrhoea and that hinders food consumption. This is supported by the following quotation from the patient:

"Since my daughter started ART he is troubled by vomiting and frequent diarrhoea and it worries me because she vomits whatever food she is taking including the medication, so how will she be cured? Sometimes she managed to eat without vomiting but immediately after eating he pass loose stools, that is really a problem to me"

Studies revealed that medication side effects can negatively affect food consumption and nutrient absorption. ARV side effects like nausea and loss of appetite may reduce food consumption, and side effects such as diarrhoea and vomiting may increase nutrient losses.

\section{Theme 2: Shortage of food due to altered socio-economic status}

Participants stated that they have a challenge regarding the means of getting well balanced diet as they were told by health workers that they are important in the management of HIV positive patients. It was also supported by [2] that good nutrition gives strength, helps to maintain and improve performance of the immune system thereby protecting the body against infection and delaying progression of the disease. According to U.S. Department of State (2006). HIV affects nutritional status by increasing energy requirements, reducing food intake, and adversely affecting nutrient absorption and metabolism: participants responded as follows:

"Despite the fact that I was told at the hospital to give my son a well-balanced diet, I am not able to buy. I do not have money as I am not working, I can only afford to buy a bag of meal- meal for the whole family with the money I get from my pension grant"

Adequate nutrition, which is best achieved through consumption of a balanced healthy diet, is vital for health and survival for all individuals regardless of HIV status. So with PLWHIV, energy intake increase with about $20 \%$ to $30 \%$ for adults during periods of symptomatic disease or opportunistic infection to maintain body weight [8].

\section{Sub theme 2.1 No income as the patient is unable to secure job because of the disease process}

Participants voiced out that their HIV positive patients are not working because they are unable to secure job due to their physical unfit, as a results they do not have money to buy food. Participant responded in the following way:

"My son was well employed in Town; he was able to support himself and his family, he was dismissed from his work as he was unable to work because of this disease. Since he is not working, there is no money to buy food. I used the money from my pension to support his family and is not enough because he has his wife and three children and I also have two young children. It is really difficulty"

This is also supported by the study conducted in Zimbabwe which revealed that; HIV/AIDS and poor nutrition lowers a person's capacity to recover from infections, thereby leading to even further reductions in a household's food supply. Infected individuals suffering from malnourishment are more likely to develop AIDS-related illnesses that diminish their ability to support dependent household members [3].

Malnutrition increases fatigue and decreases physical activity in people living with HIV and erodes household Livelihoods through a reduced ability to work and earn an income for food [3].

Katherine et al. indicated that food insecurity implies lack of physical and/or economic access to food of sufficient quality or quantity [9]. Meaning that the physical well-being and economic status of HIV patients have great influence on food security. Merrill supported that when a family member falls ill to HIV disease household earnings shrink. Healthy family members must find time and energy to care for their partners or other household relatives, further decreasing the amount of household labour available for food or income production [10].

\section{Sub theme 2.2. Lack of financial support by other members of the affected family.}

Participants indicated that they lack support from other members of the family. For example a father who didn't want to support his son; after he discovered that his son is HIV positive. Participant responded as follows:

Since that day he never wanted to see him, he stopped paying his school fees, since then he has never sent money or just to come home, he is no longer involved in anything in the family including buying food; he does not want to do anything with his family anymore. So where can I get money for food"

According to study conducted in rural America, Food insecurity was more prevalent among families with a lower total household income and those with the parent not currently employed for pay Katherine et al (2012) The results are similar to the findings of this study which was conducted in Vhembe district of Limpopo province, South Africa [9].

\section{Theme 3: Insufficient knowledge regarding the relationship between HIV and nutrition}

Participants showed insufficient knowledge regarding the relationship between HIV and nutrition Food insecurity and inadequate knowledge of good nutrition impede management of the disease, particularly in resource-constrained settings where HIV is prevalent and health care services remain inadequate [2]. 
Citation: MCur TAR, Netshikweta ML (2014) Food Insecurity Among HIV Sero-Positive Patients. J Nurs Care 3: 178. doi:

Page 4 of 4

\subsection{Knowledge about the importance of well-balanced diet and types of food.}

Most of the participants showed that they do not even know what a well- balanced diet is, with them; if a person is eating it is ok Participant's responded in this way:

"At the hospital I was told to give her (patient) a well-balanced diet and I do not know which ones are the well-balanced diets. I give her pap with vegetable daily but I sometimes give her pap with meat and I am really not sure whether it is a well- balanced diet"

Participants do not know the types of food that they are supposed to give to their relatives who are HIV positive. They just believe that even if the patient is continuing to eat one category of food it will be enough for the health of their patients. Another Participant's responded in this way:

"My son prefers to eat pap with Maas, and sometimes with meat and vegetables, he does not want to eat fruits as I sometimes buy them. But I think it is still ok because he is eating what he likes; I don't know is it not ok"

Education is crucial for improving understanding of the interaction of nutrition and HIV infection, and the impact of nutrition interventions on preventing and managing HIV infection [8] (Table $1)$.

\section{Conclusion}

This study revealed that participantsexperience problems because their patients are unable to eat due to lack of appetite, vomiting, oral thrush and depression which often accompany HIV infection. They also have challenges regarding the means of getting well balanced diet which is important in the management of HIV positive patients. Moreover they have showed insufficient knowledge regarding the relationship between HIV and nutrition. Nutritional care and support, which includes counselling, education, information-sharing and provision of food, is therefore a fundamental component of a comprehensive package of care and support for all PLHIV [9-13].

\section{References}

1. Mashau N.F (2006) Investigation into knowledge. Attitude and heath practice of students towards sexually transmitted diseases: human Immunodeficiency Virus and Acquired Immunodeficiency syndrome at a tertiary institution in the Northern Province. Unpublished Masterâ $€^{\mathrm{Tw}} \mathrm{s}$ Dissertation, University of Venda, Thohoyandou, South Africa.

2. WHO (2009). Guidelines for an Integrated Approach to the Nutritional care of HIV-infected children (6 months-14 years). Handbook (PP 33-35). Geneva, Switzerland.

3. UNAIDS (2010). Epidemiological Fact Sheet on HIV and AIDS.

4. WHO (2006a). antiretroviral therapy for HIV infection in adults and adolescents in resource limited settings: towards universal access. Recommendation for a health approach: Geneva.

5. Tshililo A.R (2006) The experiences of family members in caring for HIV/AIDS patients at home in Vhembe district of Limpopo province . University of Venda, Thohoyandou South Africa.

6. Brink H (2006) Fundamentals of research methodology for nurses 2: 113-118

7. Creswell JW (2009) Research design: Qualitative, quantitative and mixed methods approach (100-112). Thousand Oaks, California: Sage.

8. Polit DF, Beck CT (2006) Essentials of nursing research: methods, appraisal, and utilization. 6th edition. Philadelphia: Lippincott Williams \&Wilkins

9. WHO (2003) Nutrient requirements for people living with HIV/AIDS: Report of a technical consultation. GENEVA.

10. Katherine W, Bauer MS, Widome MS, John H, Himes MS, et al. (2012) High Food Insecurity and Its Correlates Among Families living on a Rural American Indian Reservation American Journal of Public Health 102: 1346-1352.

11. Merrill S (2004) Towards a critical biosocial model of eco health in Southern Africa: the HIV/AIDS and nutrition insecurity syndemic.

12. Weiser SD, Leiter K, Bangsberg DR, Butler LM, Percy-de Korte F, et al. (2007) Food insufficiency is associated with high-risk sexual behavior among women in Botswana and Swaziland. PLoS Med 4: 1589-1597.

13. WHO (2005) Consultation on nutrition and HIV/AIDS in Africa: Evidence, lessons, and recommendations for action. 